\title{
Naive CD8+ T cells from ART respond to primary vaccination against autologous HIV-1 antigen
}

\author{
Kellie N Smith ${ }^{1 *}$, Robbie B Mailliard ${ }^{2}$, Weimin Jiang ${ }^{2}$ \\ From 17th International Symposium on HIV and Emerging Infectious Diseases (ISHEID) \\ Marseille, France. 23-25 May 2012
}

\section{Introduction}

Antiretroviral therapy (ART) decreases HIV-1 viremia and AIDS-associated mortality. Despite this, HIV infected patients are unable to clear virus during treatment interruption due to insufficient cytotoxic T cell (CTL) activity against the autologous reservoir. It is unclear if naïve $\mathrm{T}$ cells from patients on ART can respond to immunotherapies that induce CTL specific for their own, unique virus. Unfortunately, late-evolving virus and the ART reservoir contain escape epitope variants that confer a lack of CTL control. We hypothesize that a dendritic cell (DC)-based immunotherapy during ART can induce CTL capable of eliminating the autologous reservoir, despite their failure to do so during natural infection.

\section{Materials and methods}

We use a naïve $\mathrm{T}$ cell flow cytometry panel to evaluate changes in the naive $\mathrm{CD} 4+: \mathrm{CD} 8+\mathrm{T}$ cell ratio before seroconversion, during untreated infection, and after ART in an HIV infected subject. We then use this panel to isolate naive CD4+ and CD8 + T cells from this patient during ART and from HIV negative donors. These purified naive $\mathrm{T}$ cells are then used in an in vitro model of dendritic cell (DC) vaccination at their in vivo ratios to induce primary IFN $\gamma$-producing CTL against autologous HIV-1 Gag, Env, and Nef peptide antigens derived from ART.

\section{Results}

Although partial immune reconstitution occurs during ART, we observed a disproportionate recovery in the naïve $\mathrm{CD} 4+: \mathrm{CD} 8+\mathrm{T}$ cell ratio compared to pre-infection. Despite this, we show that naïve CD4+ and CD8+ $\mathrm{T}$ cells from ART, when primed at their skewed in vivo

\footnotetext{
* Correspondence: kns27@pitt.edu

'University of Pittsburgh School of Medicine, Department of Molecular Virology and Microbiology, Pittsburgh, USA

Full list of author information is available at the end of the article
}

ratio against late-acquired, "escape" epitope variants, differentiate into IFN $\gamma$-producing CTL comparable to those induced in pre-seroconversion $\mathrm{T}$ cells. Additionally, we show that primary CTL responses induced during ART are comparable to those observed in HIV negative donors. Figure 1.

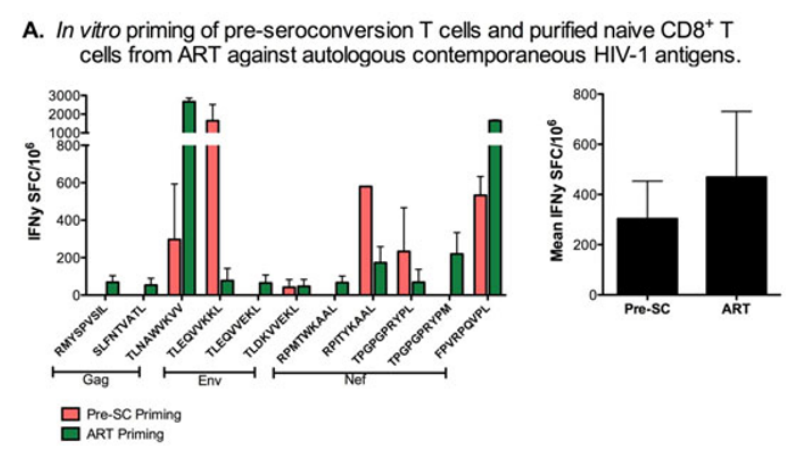

B. Primary IFNy production during ART was not statistically different from primary responses induced from naive CD8+ T cells from HIV primary responses
negative donors.
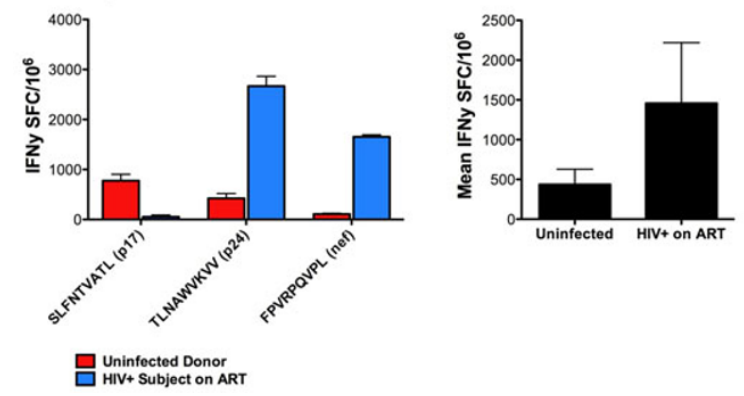

Figure 1 


\section{Conclusion}

These data indicate that, despite a disproportionate recovery in the naive $C D 4+: C D 8+T$ cell ratio, $D C$ vaccination of naïve $\mathrm{T}$ cells from ART can induce CTL specific for autologous "escape" HIV-1 variants, and that these naive $\mathrm{T}$ cells can respond to primary vaccination at a level similar to pre-infection. These data support the use of DC immunotherapies in HIV infected patients on ART.

\section{Author details}

'University of Pittsburgh School of Medicine, Department of Molecular Virology and Microbiology, Pittsburgh, USA. ${ }^{2}$ University of Pittsburgh Graduate School of Public Health, Department of Infectious Diseases and Microbiology, USA.

Published: 25 May 2012

- Convenient online submission

- Thorough peer review

- No space constraints or color figure charges

- Immediate publication on acceptance

- Inclusion in PubMed, CAS, Scopus and Google Scholar

- Research which is freely available for redistribution 